\title{
Sources of spread in simulations of Arctic sea ice loss over the twenty-first century
}

\section{A letter}

\author{
Julien Boé • Alex Hall • Xin Qu
}

Received: 21 October 2009 / Accepted: 31 January 2010 / Published online: 17 February 2010

(C) The Author(s) 2010. This article is published with open access at Springerlink.com

\begin{abstract}
We show that intermodel variations in the anthropogenically-forced evolution of September sea ice extent (SSIE) in the Arctic stem mainly from two factors: the baseline climatological sea ice thickness (SIT) distribution, and the local climate feedback parameter. The roles of these two factors evolve over the course of the twenty-first century. The SIT distribution is the most important factor in current trends and those of coming decades, accounting for roughly half the intermodel variations in SSIE trends. Then, its role progressively decreases, so that around the middle of the twenty-first century the local climate feedback parameter becomes the dominant factor. Through this analysis, we identify the investments in improved simulation of Arctic climate necessary to reduce uncertainties both in projections of sea ice loss over the coming decades and in the ultimate fate of the ice pack.
\end{abstract}

\section{Introduction}

Over the past three decades, large negative trends in sea ice extent (SIE) at the seasonal minimum have been observed in the Arctic (Serreze et al. 2007) and a spectacular record low was reached in 2007 (Zhang et al. 2008). This ice loss has created a great deal of interest in the fate of Arctic sea-ice in response to anthropogenic forcing. Figure 1 illustrates the seasonal cycle of anthropogenically-forced ice loss in current models. The losses in winter SIE at the end of the twenty-first century simulated by state-of-the-art climate models are moderate. However, large reductions are projected in late summer/early fall, with a maximum in September. The inter-model spread for this period of the year is very large. There is also a large spread in simulated present-day trends in September sea ice extent (SSIE), and most

J. Boé $(\bowtie) \cdot$ A. Hall · X. Qu

Department of Atmospheric and Oceanic Sciences,

University of California, Los Angeles, California, USA

e-mail: boe@atmos.ucla.edu 


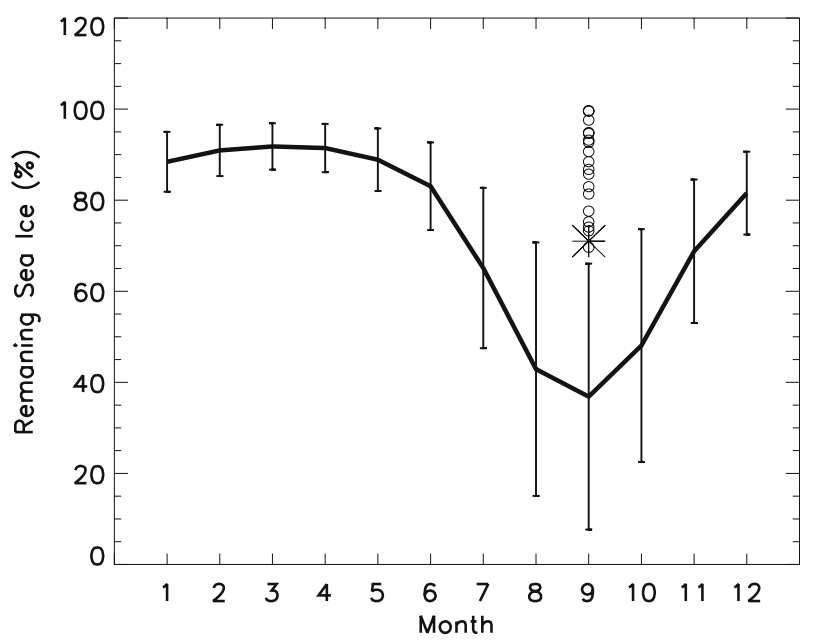

Fig. 1 Seasonal cycle of the mean percentage of remaining sea ice in 2070-2099 compared to 19701999 as simulated by 18 climate models from the Coupled Model Intercomparison Project phase 3 (CMIP3): bccr_bcm2_0, cccma_cgcm3_1, cccma_cgcm3_1_t63,cnrm_cm3, csiro_mk3_0,gfdl_cm2_0, gfdl_cm2_1, giss_aom, giss_model_e_r, inmcm3_0, ipsl_cm4, miroc3_2_medres, miub_echo_g, mpi_echam5, mri_cgcm2_3_2a, ncar_ccsm3_0, ukmo_hadcm3, ukmo_hadgem1. Observed forcing are used for the twentieth century ("20C3M" experiments) and the SRESA1B scenario is used for the twenty-first century. The line stands for the ensemble mean and the error bars stand for one inter-model standard deviation. The circles show the following values: $[100 \%$ minus the relative loss of SSIE in \% over the 1979-2007 period] in the models; the star corresponds to the observed value. SIE observations used in this paper comes from satellite passive microwave observation (Cavalieri et al. 1996)

climate models seriously underestimate the magnitude of these trends (Stroeve et al. (2007) and Fig. 1). It is possible to combine current model results and observations to project the future evolution of SIE and reduce the associated uncertainties (Boé et al. 2009a). But in the long term, climate models must be improved to obtain more credible and accurate projections of the evolution of Arctic climate. This is also important in a larger context: since the evolution of Arctic sea ice cover likely has important climate effects at lower latitudes (Hall 2004), for example through largescale circulation changes (Gerdes 2006; Honda et al. 2009), uncertainties surrounding it amplify climate change uncertainties in other regions.

A first step towards improving climate models is understanding the mechanisms responsible for the large spread in anthropogenically-forced SIE changes, and for the underestimation of present-day trends in September by most models. In Boé et al. (2009b), we found that most current climate models probably simulate excessive negative feedback in the Arctic, and consequently may underestimate nearequilibrium Arctic climate change, including loss of sea ice. It is tempting to conclude that this underlies the failure of the models to simulate recent SSIE trends. But the correlation between the climate feedback parameter in the Arctic and simulated present-day SSIE trends, though of the expected sign, is weak $(-0.33)$ (Boé et al. 2009b). Present-day SSIE trends being relatively insensitive to near-equilibrium radiative feedbacks, it is very likely that radiative feedbacks are not the main reason for their underestimation by most models. Other mechanisms must be important. 
Several studies pointed to the role of present-day ice properties (thickness, extent) on the evolution of sea ice cover under anthropogenic forcing (Rind et al. 1995; Holland and Bitz 2003; Holland et al. 2006a). Recently, Bitz (2008) showed that changes in sea ice thickness (SIT) are larger in models with thicker present-day ice but Holland et al. (2008) indicated that although models with thicker present-day ice generally simulate larger ice volume changes, it translates into only small changes in extent in September. They also suggested that discrepancies between simulated and actual baseline SIT may contribute to the underestimation of SSIE trends noted by Stroeve et al. (2007).

A first objective of this study it to quantify more precisely the role of baseline SIT on sea ice loss in September. A second objective is to reconcile evidence demonstrating the importance of radiative feedbacks for long-term simulated Arctic ice loss change with evidence pointing to the controlling influence of baseline climatological ice properties for simulations of recent ice loss. In particular, we explore the possibility that the mechanisms governing the evolution of sea ice in the Arctic under anthropogenic forcing and its uncertainties are time-dependent.

\section{Present-day trends}

To begin, we examine the baseline SIT distribution in September over the period from 1950 to 1979 in each CMIP3 model (Fig. 2a). The distribution is given as the percentage of total September ice cover constituted by ice whose thickness falls within $0.5 \mathrm{~m}$ bins (noted below as Area [thickness bin]). The ensemble mean distribution has roughly two modes, one corresponding to very thin ice (thickness $<$ $0.5 \mathrm{~m}$ ), and another corresponding to 1-2 $\mathrm{m}$ thick ice. More significant is the very large inter-model spread in SIT distribution, also seen in the cumulative distribution (inset in Fig. 2a). For example, in one model more than $80 \%$ of the ice cover is thinner than $0.5 \mathrm{~m}$ while in another models, most ice is thicker than $3 \mathrm{~m}$. This is important in the context of present-day SSIE trends because, as shown in Fig. 2b, the trend in sea ice concentration (SIC) varies significantly with SIT in the ensemble mean. In almost all models, trends in SIC are very small in thick ice areas while large trends are seen in thin ice areas. Thin ice areas are more sensitive to a given increase in radiative forcing because a smaller volume of ice must be melted to achieve the same loss of ice covered area as in thick ice areas. In addition, areas of thin ice have a greater susceptibility to albedo feedback (Holland et al. 2006b). Biases in a particular model that lead to excessive SIT in the present climate (for example errors in surface energy budget, underestimation of poleward heat transport by the ocean and the atmosphere, storms that are too weak or too infrequent etc.) may play in the future climate, potentially slowing sea ice loss.

Given the large model-to-model variations in SIT distribution (Fig. 2a) and the evident sensitivity of SIC trends to the baseline SIT distribution (Fig. 2b), the intermodel spread in the baseline SIT distribution ought to play an important role in SSIE trends in the CMIP3 models. To test this, we correlated the SSIE trends in the 1979-2007 period in the CMIP3 models to Area [thickness bin] for each thickness bin (Fig. 2c, solid line). Models where thin ice occupies a large percentage of area are characterized by larger negative SSIE trends, while a high areal coverage of thick ice is associated with smaller negative trends, confirming our hypothesis. In particular, 
(a)

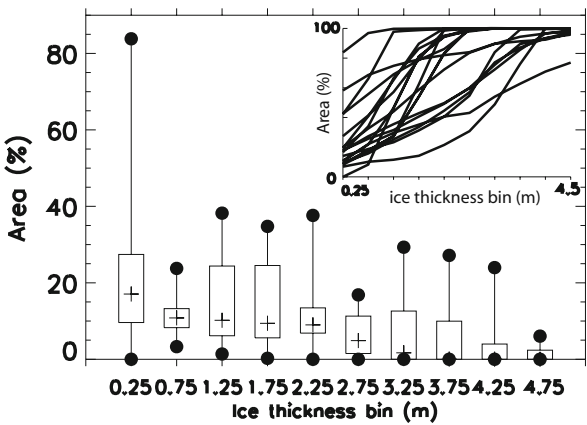

(c)

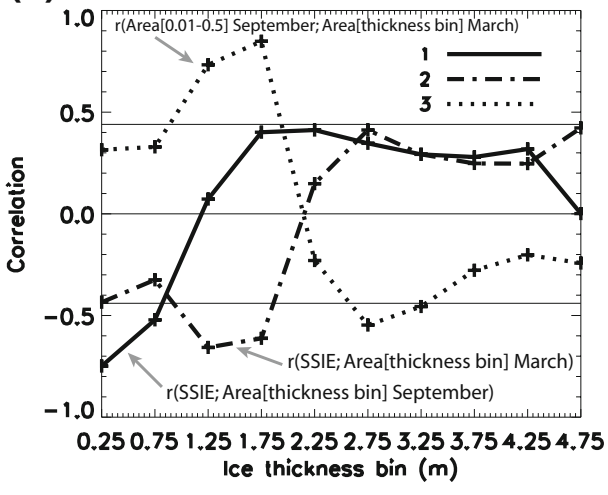

(b)

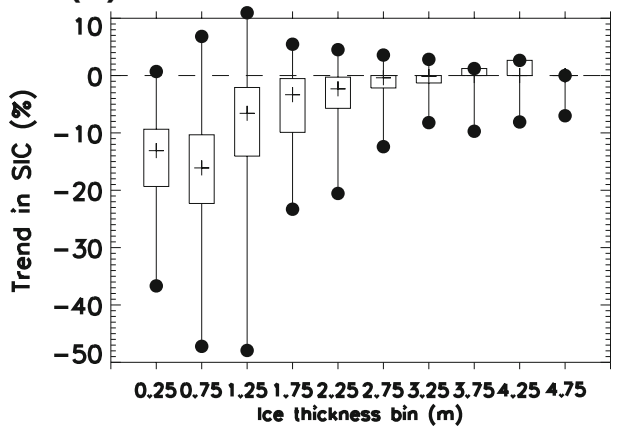

(d)

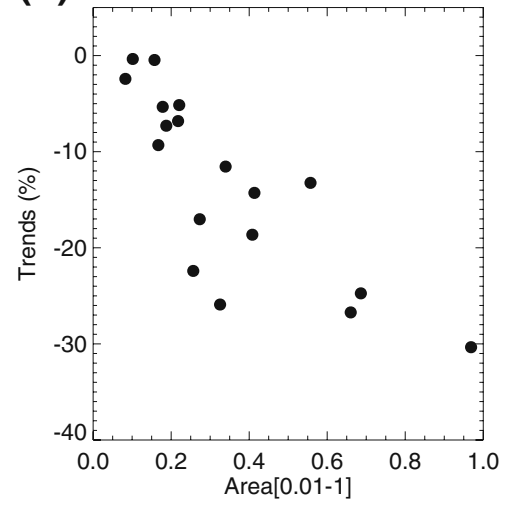

Fig. 2 a SIT distribution in the 1950-1979 period in the CMIP3 models (see text for details). Here, we consider the area of all grid cells where the mean SIT is greater than 0. The box and whisker plot shows the maximum and the minimum values among the models as well as the 25th and 75th quartile and the median. The inset shows the cumulative distribution corresponding to each model. b Mean trend in sea ice concentration (SIC) on the 1979-2007 period for each ice thickness bin, in ensemble mean. c 1 Intermodel correlation of SSIE trends in the 1979-2007 period (relative to the 1979-2007 average) with the percentage of total ice cover each thickness bin represents in the 19501979 period in September. 2 Intermodel correlation of SSIE trends in the 1979-2007 period (relative to the 1979-2007 average) with the percentage of total ice cover each thickness bin represents in the 1950-1979 period in March. 3 Intermodel correlation of the climatological proportion of very thin ice in September ([0.01-0.5 m] range) with the percentage of total ice cover each thickness bin represents in the 1950-1979 period in March. The $x$-axis values are the centers of the $0.5 \mathrm{~m}$ thickness bin. The thin horizontal lines show the 0.05 confidence level. d Simulated SSIE trends in the 1979-2007 period (relative to the 1979-2007 average) versus the proportion of thin ice (0.01-1 m range) in September in the 1950-1979 period

a large baseline proportion of thin ice in September (large Area [0.01-0.5] and Area [0.5-1]) is associated with larger negative trends, as it is also seen in Fig. $2 \mathrm{~d}$.

The September SIT distribution is closely related to the simulated SIT distribution in other seasons. For example, we correlated the proportion of $0.01-0.5 \mathrm{~m}$ thick ice in September in the CMIP3 models to the climatological SIT distribution in the opposite phase of the seasonal cycle (March) and found that a high proportion of $1-2 \mathrm{~m}$ thick ice in March is closely associated with a large proportion of $0.01-0.5 \mathrm{~m}$ thick ice in September (Fig. 2c, dotted line). Apparently, in most models, ice in the 
1-2 $\mathrm{m}$ thickness category at ice maximum becomes the thinnest ice when minimum ice extent occurs. This accounts for the high anti-correlation between SSIE trend in the 1979-2007 period and the baseline proportion of 1-2 $\mathrm{m}$ thick ice in March (dashed dotted line) in the CMIP3 models.

The strong dependence of the trends in SIC in September on the thickness distribution (Fig. 2b) suggests that the resolution and / or parameterization of subgrid scale thickness distribution of the sea ice model may influence significantly the simulation of sea ice loss. Given the strong relation between SSIE trends and the baseline SIT distribution throughout the seasonal cycle in the CMIP3 models, it is highly probable that the underestimation of present-day trends by most models is due to an unrealistic baseline SIT distribution. Most models probably underestimate the proportion of very thin ice in September, a reflection of an unrealistic seasonal cycle of SIT. Efforts to validate and improve SIT distribution must therefore address the entire seasonal cycle of sea ice holistically. Unfortunately, despite important recent progresses, with the development of satellite products (Kwok and Cunningham 2008), the temporal and / or spatial sampling of SIT observations are still limited and not sufficient to robustly assess the realism of the baseline climatological baseline SIT distribution in climate models.

\section{Evolution of uncertainties during the twenty-first century}

In the previous section, we showed that the baseline SIT distribution is a principal cause of spread in simulated present-day trends in SSIE. In Boé et al. (2009b), a climate feedback parameter $(\lambda)$ local to the Arctic was found to tightly control near-equilibrium sea ice change, as well as other important features of Arctic climate change. An explanation reconciling these two results is that the mechanisms controlling inter-model variations in SSIE changes evolve over the course of the climate changes simulations. This explanation is tested in this section.

In Boé et al. (2009b) a definition of the radiative feedback parameter adapted to the peculiarities of the Arctic was developed. The same definition is adopted here:

$$
\lambda=\frac{\Delta F}{\Delta T_{o c}}+\frac{\Delta Q}{\Delta T_{o c}}
$$

$\Delta T_{o c}$ is the annual mean change in oceanic temperature in the uppermost $70-\mathrm{m}$ of ocean, $\Delta Q$ the annual change of net shortwave radiation at the top of atmosphere (TOA) and $\Delta F$ the annual change of longwave radiation at the TOA, the direct radiative forcing of $\mathrm{CO}_{2}$ being removed first (Intermodel variations in the radiative forcing of $\mathrm{CO}_{2}$ are not taken into account). Those changes are computed to correspond as closely as possible to an equilibrium climate change experiment, i.e. between 2150-2199 and 1900-1949. (Note that the radiative forcing is fixed in the SRESA1B scenario at year 2100). We first average $\Delta T_{o c}, \Delta Q, \Delta F$ over latitudes greater than $70 \mathrm{~N}$ and then compute the ratios in (1).

We showed in Boé et al. (2009b) that this metric for the feedback parameter is more appropriate to predict and understand near equilibrium climate change in the Arctic than the traditional metric defined using change in air surface temperature (i.e. $\Delta T_{a s}$ in (1) rather than $\Delta T_{o c}$ ). The reason for this is that in the Arctic, $\Delta T_{a s}$ is not the most representative and relevant metric of changes in the energy content 
of the atmosphere/oceanic mixed layer system. Indeed, Arctic ice cover hampers an efficient coupling between ocean and atmosphere via surface heat fluxes, and the thermal inversion during winter prevents the vertical homogenization of atmospheric temperature changes. More details concerning the comparison of these two metrics and about the metric used in the current paper can been found in Boé et al. (2009b).

Due to data availability, $\lambda$ can be computed only in a subset of 12 models. Therefore, the analysis here is primarily done using these models. For each overlapping 20year period between 2005 and 2100, we correlated the mean percentage of remaining SIE in September in the models to Area [0.01-1] and $\lambda$ (Fig. 3a). Area [0.01-1] in the 1950-1979 period accounts for almost 60\% of the variance in SSIE trends in the 1979-2007 period (see Section 2) and roughly 55\% of the variance in SSIE changes at the beginning of the twenty-first century (Fig. 3a). Then, the role of Area [0.01-1] decreases slowly during the twenty-first century. Part of the decrease in the correlation between Area [0.01-1] and SSIE change is due to the fact that the relationship between Area [0.01-1] and SSIE changes becomes increasingly nonlinear during the twenty-first century, especially at century's end, when the first models come near to ice-free conditions (not shown). This effect not withstanding, the absolute correlation between SSIE changes and the proportion of thin ice in the models remains significant even at the end of the twenty-first century. The subset of 12 models behaves similarly to the larger ensemble (dashed line, Fig. 3a). Bitz (2008) and Holland et al. (2008) showed that as changes in SIT are larger in models with thicker ice in baseline climate, the initial differences in SIT among the models tend to decrease during the twenty-first century, which is consistent with a decrease of the role of the baseline SIT distribution in SSIE changes over time.

While the role of the baseline SIT distribution in the spread of SSIE change decreases, the climate feedback parameter becomes more and more important. $\lambda$ explains only $20 \%$ of the inter-model spread in SSIE changes at the beginning of the twenty-first century, but then its role progressively increases. By the end of the

(a) September

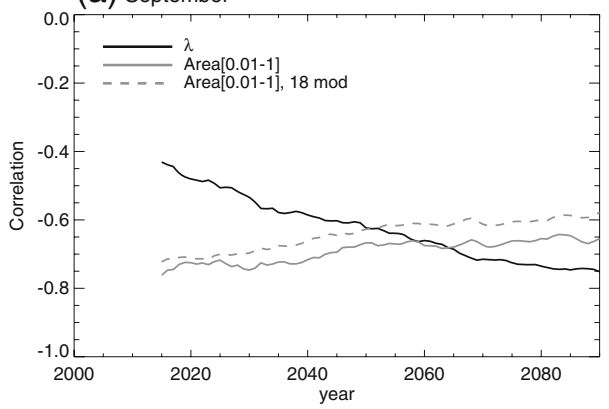

(b) Annual

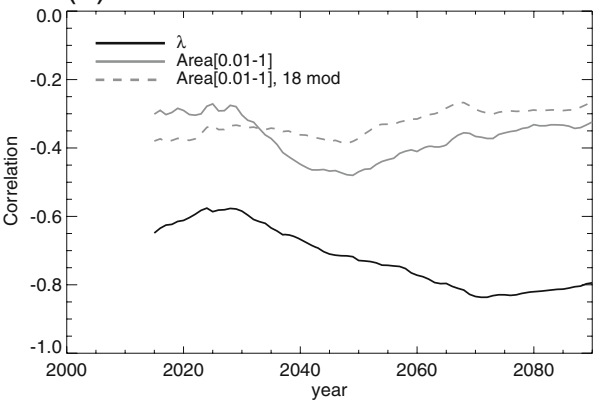

Fig. 3 a Correlation of the percentage of remaining sea ice in September the reference being the 1979-2007 period with Area [0.01-1] in the 1950-1979 period and $\lambda$ for every overlapping 20-year periods in the twenty-first century (see text for details). A subset of 12 models is used. The correlation of the percentage of remaining sea ice in September with Area [0.01-1] in the 1950-1979 period when the 18 models are used is also shown. b As (a) for the percentage of remaining sea ice at the annual level 
twenty-first century, $\lambda$ explains almost $60 \%$ of the inter-model spread. Since Area [0.01-1] and $\lambda$ are almost linearly independent (correlation of 0.19), most of the spread of SSIE changes during the entire twenty-first century is explained by these two parameters only.

The increasing importance of the role of the feedback parameter $\lambda$ during the transient period is not unexpected. Initially, the SIT distribution is the most important factor in SSIE changes, because even in models with strong positive radiative feedbacks, changes in sea ice extent will be necessarily very limited at the beginning if the baseline sea ice is very thick. Radiative feedbacks only slowly become important as the climate system and in particular the sea ice cover adjust to their cumulative effects.

The same analysis is repeated replacing September SIE by the annual mean to investigate to what extent the previous results are relevant to the behavior of the entire year's ice pack (Fig. 3b). The relationship between the climate feedback parameter and the annual mean ice loss is very similar to the relationship between $\lambda$ and September ice loss. $\lambda$ explains between $30 \%$ and $40 \%$ of the variance in annual SIE changes at the beginning of the twenty-first century and its role then progressively increases, explaining more than $60 \%$ of variance at the end of the twenty-first century. The correlation then remains almost constant until the end of the twenty-second century (not shown). Interestingly, the link between Area [0.011] in September and annual mean SIE changes is weak despite the important role of Area [0.01-1] in sea ice loss in September, suggesting that the baseline proportion of thin ice is not an important factor in sea ice loss during the season of sea ice growth.

We showed that the baseline SIT distribution and the local climate feedback parameter-two factors mostly uncorrelated with one another-together explain most of the spread in sea ice loss through the twenty-first century. However, other mechanisms like changes in oceanic or atmospheric heat transport, inter-model differences in radiative forcing, differences in storm activity (Simmonds et al. 2008) not considered here can still play a role on the spread of sea ice loss, especially at the beginning of the twenty-first century and in an annual-mean sense, where the role of $\lambda$ and sea ice thickness distribution is more limited.

\section{Discussion}

As models might share some common deficiencies, the final realism of climate projections might depend on mechanisms that do not play on the inter-model spread. However, reducing the spread remains an important step towards more reliable climate change projections. In this objective, as a first step, understanding causes of uncertainties in changes of Arctic sea ice cover is necessary. Our results indicate the need for targeted investments in improved simulation of Arctic climate. The payoff from these investments depends on which aspect of Arctic climate is targeted. To improve projections of September ice loss over the next few decades, improving representation of SIT distribution is clearly an important priority. It is a challenging task because the SIT distribution results from the interplay of many different mechanisms (radiative budget, storm activity, atmospheric and oceanic heat transport, cryospheric processes etc.) The paucity and / or limitations of SIT, 
radiative fluxes, and ocean heat transport observations is also a major issue in this context. Clearly there is a need for sustained measurement of SIT and other relevant variables, coordination and public release of observational data sets, and model development efforts emphasizing realism in SIT. Investments in greater realism of simulated radiative feedbacks in the Arctic are essential to reduce uncertainty surrounding the ultimate fate of the Arctic ice pack. In Boé et al. (2009b) we showed that the clear-sky negative longwave feedback is especially important in near-equilibrium climate change in the Arctic. Moreover, this feedback is strongly linked to the baseline climatological strength of the lower atmospheric inversion. Model errors in this feature of Arctic climate indicate longwave feedbacks are generally overestimated in the Arctic. This may arise from errors in simulation of the radiative budget, the atmospheric boundary layer, or heat fluxes through the ice pack. More work in these directions is needed to improve sea ice prediction on multidecadal to centennial time scales.

Acknowledgements The authors are supported by NSF ARC-0714083. Opinions, findings, conclusions, or recommendations expressed here are those of the authors and do not necessarily reflect NSF views. We acknowledge the modeling groups, the PCMDI and the WCRP's WGCM for their roles in making available the CMIP3 dataset.

Open Access This article is distributed under the terms of the Creative Commons Attribution Noncommercial License which permits any noncommercial use, distribution, and reproduction in any medium, provided the original author(s) and source are credited.

\section{References}

Bitz CM (2008) Some aspects of uncertainty in predicting sea ice retreat. In: deWeaver E, Bitz CM, Tremblay B (eds) Arctic Sea ice decline: observations, projections, mechanisms, and implications. AGU Geophysical Monograph Series, vol 189, p 269

Boé J, Hall A, Qu X (2009a) September sea-ice cover in the Arctic Ocean projected to vanish by 2100. Nature Geosci 2:341-343

Boé J, Hall A, Qu X (2009b) Current GCM's unrealistic negative feedback in the Arctic. J Climate 22:4682-4695

Cavalieri D, Parkinson C, Gloersen P, Zwally HJ (1996) Sea ice concentrations from Nimbus-7 SMMR and DMSP SSM/I passive microwave data. Boulder, Colorado USA: National Snow and Ice Data Center. Digital media (updated 2008)

Gerdes R (2006) Atmospheric response to changes in Arctic sea ice thickness. Geophys Res Lett 33:L18709. doi:10.1029/2006GL027146

Hall A (2004) Role of surface albedo feedback in climate. J Climate 17:1550-1568

Holland MM, Bitz CM (2003) Polar amplification of climate change in coupled models. Clim Dyn 21:221-232

Holland MM, Bitz CM, Hunke EC, Lipscomb WH, Schramm JL (2006a) Influence of the sea ice thickness distribution on polar climate in CCSM3. J Climate 19:2398-2414

Holland MM, Bitz CM, Tremblay B (2006b) Future abrupt reductions in the summer arctic sea ice. Geophys Res Lett 33:L23503. doi:10.1029/2006GL028024

Holland MM, Serreze MC, Stroeve J (2008). The sea ice mass budget of the Arctic and its future change as simulated by coupled climate models. Clim Dyn (published online). doi:10.1007/s00382-008-0493-4

Honda M, Inoue J, Yamane S (2009) Influence of low Arctic sea-ice minima on anomalously cold Eurasian winters. Geophys Res Lett 36:L08707. doi:10.1029/2008GL037079

Kwok R, Cunningham GF (2008) ICESat over Arctic sea ice: estimation of snow depth and ice thickness. J Geophys Res 113:C08010. doi:10.1029/2008JC004753

Rind D, Healy R, Parkinson C, Martinson D (1995). The role of sea ice in 2xCO2 climate model sensitivity. Part I: the total influence of sea ice thickness and extent. J Climate 8:449-463 
Serreze MC, Holland MM, Stroeve J (2007) Perspectives on the Arctic's shrinking sea-ice. Science 5818:1533-1536

Simmonds I, Burke C, Keay K (2008) Arctic climate change as manifest in cyclone behavior. J Climate 21(22):5777-5796

Stroeve J, Holland MM, Meier W, Scambos T, Serreze M (2007) Arctic sea ice decline: faster than forecast. Geophys Res Lett 34:L09501. doi:10.1029/2007GL029703

Zhang J, Lindsay R, Steele M, Schweiger A (2008) What drove the dramatic retreat of arctic sea ice during summer 2007. Geophys Res Lett 35:L11505. doi:10.1029/2008GL034005 